\title{
Altered Excitability and Local Connectivity of mPFC-PAG Neurons in a Mouse Model of Neuropathic Pain
}

\author{
기ohn Cheriyan and $\odot$ Patrick L. Sheets \\ Department of Pharmacology and Toxicology and Stark Neurosciences Research Institute, Indiana University School of Medicine, Indianapolis, Indiana \\ 46202
}

The medial prefrontal cortex (mPFC) plays a major role in both sensory and affective aspects of pain. There is extensive evidence that chronic pain produces functional changes within the mPFC. However, our understanding of local circuit changes to defined subpopulations of mPFC neurons in chronic pain models remains unclear. A major subpopulation of mPFC neurons project to the periaqueductal gray (PAG), which is a key midbrain structure involved in endogenous pain suppression and facilitation. Here, we used laser scanning photostimulation of caged glutamate to map cortical circuits of retrogradely labeled cortico-PAG (CP) neurons in layer 5 (L5) of mPFC in brain slices prepared from male mice having undergone chronic constriction injury (CCI) of the sciatic nerve. Whole-cell recordings revealed a significant reduction in excitability for L5 CP neurons contralateral to CCI in the prelimbic (PL), but not infralimbic (IL), region of mPFC. Circuit mapping showed that excitatory inputs to L5 CP neurons in both PL and IL arose primarily from layer 2/3 (L2/3) and were significantly reduced in CCI mice. Glutamate stimulation of L2/3 and L5 elicited inhibitory inputs to CP neurons in both PL and IL, but only L2/3 input was significantly reduced in CP neurons of CCI mice. We also observed significant reduction in excitability and L2/3 inhibitory input to CP neurons ipsilateral to CCI. These results demonstrating region and laminar specific changes to mPFC-PAG neurons suggest that a unilateral CCI bilaterally alters cortical circuits upstream of the endogenous analgesic network, which may contribute to persistence of chronic pain.

Key words: circuit mapping; mouse; mPFC; nerve injury; neuropathic pain; PAG

\section{Significance Statement}

Chronic pain is a significant unresolved medical problem that is refractory to traditional analgesics and can negatively affect emotional health. The role of central circuits in mediating the persistent nature of chronic pain remains unclear. Local circuits within the medial prefrontal cortex $(\mathrm{mPFC})$ process ascending pain inputs and can modulate endogenous analgesia via direct projections to the periaqueductal gray (PAG). However, the mechanisms by which chronic pain alters intracortical circuitry of mPFC-PAG neurons are unknown. Here, we report specific changes to local circuits of mPFC-PAG neurons in mice displaying chronic pain behavior after nerve injury. These findings provide evidence for a neural mechanism by which chronic pain disrupts the descending analgesic system via functional changes to cortical circuits.

\section{Introduction}

The medial prefrontal cortex (mPFC) integrates sensory, affective, and attentional components of pain perception (Rainville et al., 1997; Lorenz et al., 2002; Porro et al., 2002; Qu et al., 2011;

Received Sept. 22, 2017; revised March 9, 2018; accepted March 20, 2018.

Author contributions: J.C. and P.L.S. wrote the first draft of the paper; J.C. and P.L.S. edited the paper; J.C. and P.L.S. designed research; J.C. and P.L.S. performed research; J.C. and P.L.S. analyzed data; I.C. and P.L.S. wrote the paper.

This work was supported by National Institutes of Health (Grant R01-NS094389 to P.L.S.). We thank Michael DiGaetano (University of Notre Dame) for support with experiments and data analysis.

The authors declare no competing financial interests.

Correspondence should be addressed to Dr. Patrick L. Sheets, Indiana University School of Medicine, Neuroscience Research Building 400 D, 320 West $15^{\text {th }}$ St, Indianapolis, IN 46202. E-mail: plsheets@iupui.edu.

DOI:10.1523/JNEUROSCI.2731-17.2018

Copyright $\odot 2018$ the authors $\quad 0270-6474 / 18 / 384829-11 \$ 15.00 / 0$
Bushnell et al., 2013) and therefore has become a significant focus of chronic pain research. In humans, neuropathic pain alters the structure, chemistry, and connectivity of the mPFC (Apkarian et al., 2004; Apkarian, 2004; Baliki et al., 2006). More specifically, prolonged pain results in reduced activation or increased inhibition of mPFC (Jones and Derbyshire, 1997; Derbyshire et al., 1999; Mayer et al., 2005). Epigenetic, morphological, and functional changes across multiple $\mathrm{mPFC}$ regions are observed in rodent models of pain (Cao et al., 2009; Metz et al., 2009; Alvarado et al., 2013; Blom et al., 2014; Alvarado et al., 2015; Cordeiro Matos et al., 2015; Zhang et al., 2015; Kelly et al., 2016; Kiritoshi et al., 2016). In addition, reduced mPFC activity is implicated in affective and cognitive disturbances associated with chronic pain (Millecamps et al., 2007; Ji et al., 2010; CardosoCruz et al., 2013; Lee et al., 2015; Wang et al., 2015). Together, this 
suggests that dysfunction of input-output processing in the $\mathrm{mPFC}$ is involved in chronic pain pathology. However, paininduced alterations to intracortical (i.e., local) circuits of defined mPFC neurons have not been examined thoroughly.

We (Ferreira et al., 2015; Cheriyan et al., 2016) and others (Shipley et al., 1991; Floyd et al., 2000; Gabbott et al., 2005) have shown that a major subpopulation of layer 5 (L5) neurons in prelimbic (PL) and infralimbic (IL) regions of the $\mathrm{mPFC}$ send projections to the periaqueductal gray (PAG). The PAG is a subcortical node within the endogenous analgesic network that suppresses ascending nociceptive signals (Basbaum and Fields, 1978; Behbehani, 1995; Millan, 2002; Benarroch, 2012). Stimulation of the mPFC can produce analgesia in rats (Hardy, 1985) which likely involves the cortico-PAG (CP) pathway (Hardy and Haigler, 1985). Further, activation of CP pathways in humans is associated with attentive and emotional modulation of pain (Valet et al., 2004; Villemure and Schweinhardt, 2010). Therefore, alterations to the circuitry of L5 CP neurons caused by peripheral nerve injury may disrupt normal function of the descending analgesic network while also affecting attentive and emotional aspects of chronic pain.

Our goal was to determine how peripheral nerve injury alters excitability and local circuitry of CP neurons in PL and IL regions of mPFC. We used chronic constriction injury (CCI) of the sciatic nerve in mice to model neuropathic pain. Concurrent with the CCI model, we injected the PAG with fluorescent retrograde tracer to identify and target CP neurons in mPFC for whole-cell electrophysiology and circuit mapping in acute brain slices. We show that CCI attenuates the excitability of PL-CP neurons but not IL-CP neurons. Mapping experiments demonstrate that CCI also significantly reduces local excitatory and inhibitory inputs to L5 CP neurons in both PL and IL cortex. Reduction in local excitatory input spans multiple cortical layers, whereas reduction of local inhibitory input to is laminar specific. Reduction in excitability of PL-CP neurons was bilateral across the mPFC. Interestingly, mapping of CCI-CP neurons in PL cortex ipsilateral to the nerve injury revealed a similar pattern in reduction of local inhibitory input, whereas local excitatory input remained unaffected. Together, our findings reveal that peripheral nerve injury induces specific changes to local excitatory and inhibitory circuit pathways of $\mathrm{mPFC}$ neurons connected to the descending analgesic network, thereby providing insight into how cortical dysfunction potentially contributes to the persistent nature of chronic pain.

\section{Materials and Methods}

Animals. Wild-type C57BL/6 male mice (total $n=94$; We confirm the source of mice as Jackson Laboratories) and transgenic mice expressing Td-tomato reporter protein specifically in somatostatin-expressing interneurons $(\mathrm{SOM}+$; total $n=10)$ or parvalbumin-expressing interneurons (PVINs; total $n=8$ ) were used in accordance with the animal care and use guidelines of Indiana University, the National Institutes of Health, and the Society for Neuroscience. To generate transgenic mice expressing the red fluorescent protein Td-Tomato specifically in $\mathrm{SOM}+$ neurons and PVINs, B6.Cg-Gt(ROSA)26Sor ${ }^{\text {tm9 } 9(C A G-t d T o m a t o) H z e / J}$ mice (Jackson Laboratories, RRID:IMSR_JAX:007909) were crossed with either B6N.Cg-Sst ${ }^{\text {tm2.1(cre)Zjh/J }}$ (RRID:IMSR_JAX:018973) or B6.129P2-

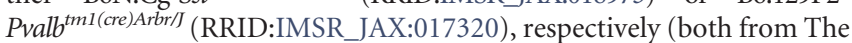
Jackson Laboratory). The Institutional Animal Care and Use Committee at Indiana University approved all experiments.

Retrograde labeling. Mice (postnatal day 24-32) were anesthetized with $1.5 \%$ isoflurane in $100 \% \mathrm{O}_{2}$ at a flow rate of $0.8 \mathrm{~L} / \mathrm{min}$ (SurgiVet Isotech 4). Body temperature was maintained at $37^{\circ} \mathrm{C}$ using a feedbackcontrolled heating pad (FHC). The head was mounted in a stereotaxic frame (Kopf Instruments). The top of the head was shaved and betadine was used to disinfect the area. A midline incision was made to the scalp to expose the skull. A Ram Power hand drill (MHC) was used to create a small craniotomy for the injection. Single injections $(75-100 \mathrm{~nL} /$ injection) of fluorescent tracers (Retrobeads; Lumafluor) were targeted throughout dorsolateral, lateral, and ventrolateral PAG regions (see Fig. $1 A-C$ ) using the UltraMicroPump controlling a Gastight 1701 Hamilton syringe paired with a beveled, two-inch, 27-gauge removable needle. We found that this strategy was ideal for adequate retrograde labeling of neurons in L5 across both PL and IL regions of mPFC. The coordinates for PAG injection were (relative to bregma; in $\mathrm{mm}$ ): 0.35 lateral, 3.2 caudal, and 3.2 deep at a $0^{\circ}$ angle. The tracers were injected at a rate of 100 $\mathrm{nL} / \mathrm{min}$. The injection syringe was left in place for $5 \mathrm{~min}$ to prevent backflow and then slowly removed. The incision was closed with VetBond $(3 \mathrm{M})$. Mice were monitored for $48 \mathrm{~h}$ after surgery to ensure their wellbeing. Animals were allowed to recover from intracranial injection for a minimum of $3 \mathrm{~d}$ (range 3-7) before induction of the neuropathic pain model.

Neuropathic pain model. The cuff variation of CCI to the sciatic nerve was used to model neuropathic pain (Yalcin et al., 2014). Briefly, the left hind leg (contralateral to the injection site of retrograde tracer into the PAG) was shaved from knee to hip. Betadine was applied to disinfect the shaved area. Under isoflurane anesthesia, an incision was made into the skin to expose the biceps femoris and gluteus muscles. These muscles were separated via a blunt dissection and the sciatic nerve was exposed and gently retracted (for sham animals, this was the surgical end point and the wound was closed as detailed below). Sterile saline $(0.09 \% \mathrm{NaCl})$ solution was used to keep the surgical site moist. A $2 \mathrm{~mm}$ section of PE-20 polyethylene tubing ( $0.38 \mathrm{~mm} \mathrm{ID/1.09} \mathrm{mm}$ OD; Harvard Apparatus) was split lengthwise on one side and placed around the sciatic nerve, which was subsequently set back in place. Surgical glue (VetBond; 3M) was used to close the incision.

Pain assessment. The behavior-testing apparatus was an elevated wire mesh platform that held 6-inch-tall, 3-inch-diameter Plexiglas tubes or 4 -inch-wide, 4.5 -inch-long, 4.5 -inch-tall glass cubicles. Mice were acclimated inside the tubes or cubicles on the wire mesh platform for 1-2 d ( $45 \mathrm{~min} / \mathrm{d}$ ) before baseline testing. On testing days, mice were acclimated to the apparatus for 30-45 min before testing began. Assessment of mechanical allodynia via paw-withdrawal threshold (PWT) was performed using standard von Frey filaments (Touch Test, VWR) in combination with the up-down method to quantify the responses in 50\% gram (Chaplan et al., 1994; Bonin et al., 2014). The baseline PWT was established after complete recovery from retrograde tracer injections but before CCI surgery. Changes in PWTs were measured on postoperative days (POD) 3 and 7.

Acute brain slice preparation. At POD7-8, acute brain slices were prepared as described previously (Ferreira et al., 2015). An off-coronal blocking cut (spine of the blade tilted rostrally $\sim 30^{\circ}$ off vertical plane) was performed for proper radial orientation of the mPFC. Coronal brain slices $(300 \mu \mathrm{m})$ containing the $\mathrm{mPFC}$ were made using a vibratome (VT1200S; Leica) in a chilled choline cutting solution containing the following (in mM): 110 choline chloride, $25 \mathrm{NaHCO}_{3}, 25$ D-glucose, 11.6 sodium ascorbate, $7 \mathrm{MgSO}_{4}, 3.1$ sodium pyruvate, $2.5 \mathrm{KCL}, 1.25$ $\mathrm{NaH}_{2} \mathrm{PO}_{4}$, and $0.5 \mathrm{CaCl}_{2}$ ). Slices were transferred to a $37^{\circ} \mathrm{C}$ artificial CSF (ACSF) bath containing the following (in $\mathrm{mm}$ ): $127 \mathrm{NaCl}, 25 \mathrm{NaHCO}_{3}$, $25 \mathrm{D}$-glucose, $2.5 \mathrm{KCl}, 1 \mathrm{MgCl}_{2}, 2 \mathrm{CaCl}_{2}$, and $\mathrm{NaH}_{2} \mathrm{PO}_{4}$ for $30 \mathrm{~min}$. Slices were subsequently incubated for at least $45 \mathrm{~min}$ in ACSF at room temperature before recording experiments.

Electrophysiological recordings. Before recording, slices were transferred into a recording chamber of a SliceScope Pro 6000 (Scientifica) paired with an upright microscope (BX51; Olympus) and PatchStar micromanipulators (Scientifica). Slices were held in place with flattened gold wire $(0.813 \mathrm{~mm}$ diameter; Alfa Aesar). Fluorescently labeled neurons were identified using an LED illumination system (CoolLED pE4000). Recording pipets were fabricated from borosilicate capillaries with filaments (G150-F; Warner Instruments) using a horizontal pipet puller (P-97; Sutter Instruments). For intrinsic recordings, pipets were filled with an internal solution containing the following (in $\mathrm{mM}$ ): 128 K-gluconate, $10 \mathrm{HEPES}, 1 \mathrm{EGTA}, 4 \mathrm{MgCl}_{2}$, 4 ATP, $0.4 \mathrm{GTP}, 10$ phosphocreatine, 3 ascorbate, and 0.05 Alexa Fluor 488 hydrazide (Invitrogen) 

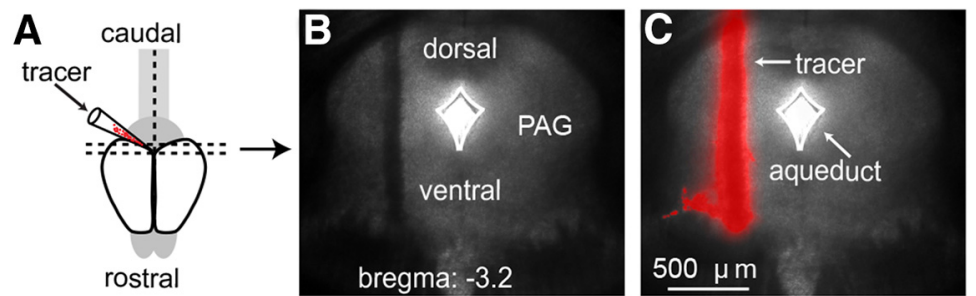

D

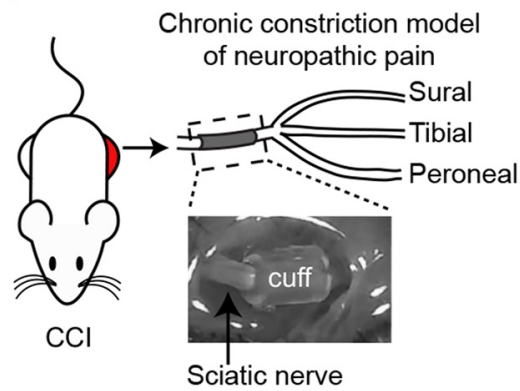

E

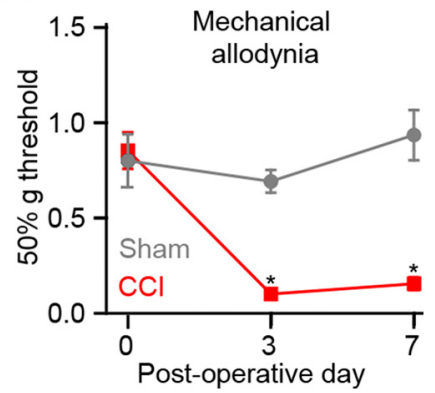

Figure 1. Identifying cortico-PAG neurons in the $C(\mathrm{Cl}$ model of neuropathic pain. $A$, Schematic depicting red retrograde tracer injection into the PAG. $\boldsymbol{B}, \boldsymbol{C}$, Representative coronal brain section ( $\boldsymbol{B}$ : bright field; $\boldsymbol{C}$ : epifluorescence) showing retrograde tracer injection into the PAG. $\boldsymbol{D}$, Image (top) and schematic (bottom) depicting the chronic constriction model of neuropathic pain involving placement of tubing ("cuff") around the sciatic nerve medial to the trifurcation into the peroneal, tibial, and sural nerves. $\boldsymbol{E}$, Assessment of mechanical allodynia after $\mathrm{CCl}$ of the sciatic nerve (control: sham surgery).

plus $4 \mathrm{mg} / \mathrm{ml}$ biocytin (Sigma-Aldrich). Whole-cell patch-clamp recordings were performed at $30-32^{\circ} \mathrm{C}$ in ACSF containing synaptic blockers: 5 mM each of gabazine (a GABAA antagonist), NBQX (an AMPA receptor antagonist), and CPP (an NMDA receptor antagonist). Pipette capacitance was compensated and inclusion of data required a series resistance $<35 \mathrm{M} \Omega($ mean $=16.3 \mathrm{M} \Omega$ ). Current-clamp recordings were bridge balanced. Recordings were amplified and filtered at $4 \mathrm{kHz}$ and digitized at $10 \mathrm{kHz}$ using a Multiclamp 700B amplifier (Molecular Devices). Ephus software (http://www.ephus.org) was used for data collection (Suter et al., 2010). Methods for determining input resistance and voltage threshold for action potential (AP) firing have been reported previously (Suter et al., 2013). Briefly, input resistance was measured as the slope of a linear least-squares fit to the voltage-current relationship established from steady-state responses to a series of hyperpolarizing and subthreshold depolarizing current steps (duration $1.0 \mathrm{~s}$, amplitude $\leq 200 \mathrm{pA}$ ). The voltage threshold for AP firing was calculated as the point when $\mathrm{d} V / \mathrm{d} t$ exceeded $10 \%$ of its maximum value relative to the mean $\mathrm{d} V / \mathrm{d} t$ baseline measured over the 5-4 ms window before the AP peak. Frequencycurrent slope was calculated using a polynomial fit to the firing frequency at current threshold through the firing frequency at twice the current threshold.

Glutamate uncaging and laser scanning photostimulation. Glutamate uncaging and laser scanning photostimulation (glu-LSPS) were performed as described previously (Anderson et al., 2010; Ferreira et al., 2015) using an ultraviolet (UV) laser (355 nm; DPSS Lasers). Stock solutions (50 mM in water) of MNI-caged glutamate (Tocris Bioscience catalog \#1490) were prepared at room temperature (to avoid precipitation) with sonication, aliquoted, and stored at $-20^{\circ} \mathrm{C}$ until use. Ephus software was used for hardware control and data acquisition (Suter et al., 2010). The bath solution for photostimulation studies contained elevated concentrations of divalent cations ( $4 \mathrm{mM} \mathrm{Ca}^{2+}$ and $4 \mathrm{mM} \mathrm{Mg}^{2+}$ ) and an NMDA receptor antagonist ( $5 \mu \mathrm{M}$ CPP; Tocris Bioscience) to dampen neuronal excitability. Gabazine and NBQX were not included in the bath solution for glu-LSPS mapping studies. Caged glutamate $(0.2$ $\mathrm{mm}$ ) was added directly to the bath solution. Voltages were not corrected for liquid junction potential. Recordings were performed at $21^{\circ} \mathrm{C}$ and were monitored for series resistance (inclusion criterion: $<35 \mathrm{M} \Omega$; mean: $17.3 \mathrm{M} \Omega$ ). Once a patch recording of a labeled neuron was established, an image of the slice $(4 \times$ objective) was acquired before mapping for precise registration of the mapping grid. The mapping grid $(16 \times 16$;
$75 \mu \mathrm{m}$ spacing) was rotated with the top row of the grid flush with the pia and the soma was centered horizontally in the grid. The grid locations were sampled (every $0.4 \mathrm{~s}$ ) with a UV stimulus $1.0 \mathrm{~ms}$ in duration and $15 \mathrm{~mW}$ at the specimen plane. For both excitatory and inhibitory mapping, patch pipettes contained cesium-based intracellular solution containing the following (in $\mathrm{mM}$ ): 128 Cs-gluconate, 10 HEPES, 1 EGTA, $4 \mathrm{MgCl}_{2}$, 4 ATP, 0.4 GTP, 10 phosphocreatine, 3 ascorbate, 1 QX-314, and 0.05 Alexa-594 or 488 hydrazide. Photostimulation sites resulting in activation of glutamate receptors on the dendrites of the recorded neuron were readily detected based on characteristically short onset latencies $(<7 \mathrm{~ms})$ of responses (Schubert et al., 2001; Anderson et al., 2010). Responses overlapped by direct activation of the recorded neuron's dendrites were excluded and rendered as black pixels in input color maps. All remaining recorded inputs with onset latencies $>7 \mathrm{~ms}$ were included in the map analyses as synaptic responses resulting from uncaged glutamate activation of presynaptic neurons within the local circuit. These maps thus represent "images" of the local sources of monosynaptic input arising from small clusters of $\sim 100$ neurons at each stimulus location. Excitatory (glutamatergic) responses were recorded at a command voltage of $-70 \mathrm{mV}$. Excitatory input maps were constructed on the basis of the mean inward current over a $0-50 \mathrm{~ms}$ poststimulus time window. Inhibitory (GABAergic) responses were recorded at a command voltage of $+10 \mathrm{mV}$. Inhibitory input maps were constructed on the basis of the mean outward current over a $0-750 \mathrm{~ms}$ poststimulus time window. The inhibitory poststimulus time window was increased due to the longer time course for inhibitory responses to return to baseline.

Experimental design and statistical analysis. Custom MATLAB (The MathWorks, RRID:SCR_001622) routines were used to analyze data offline. Normal distribution of data was determined using a Lilliefors normality test. Statistical comparisons between sham and CCI groups were performed using the Student's unpaired $t$ test for normally distributed data and the Wilcoxon's rank-sum test for non-normally distributed data. Differences were considered significant a $p<0.05$. Unless otherwise noted, results in the text are presented as mean \pm SEM. For data presented as boxplots, the box displays the central $50 \%$ of the data with the central line indicating the median and the lower/upper boundary lines being the $25 \% / 75 \%$ quantile of the data. Whiskers extend maximally to 1.5 times the height of the box but do not extend past the range of the data. Outliers are indicated by "+."

\section{Results}

Nerve injury reduces intrinsic excitability of CP neurons in the prelimbic, but not infralimbic, region of $\mathrm{mPFC}$

To identify CP neurons in the mPFC, we stereotaxically injected red fluorescent Retrobeads into the PAG in vivo several days before the CCI or sham procedure (Fig. $1 A-D$ ). We observed significant mechanical allodynia in the hindpaw ipsilateral to the CCI on POD3 that persisted through POD7 (Fig. 1E). At POD78 , acute brain slices containing $\mathrm{MPFC}$ were prepared for wholecell electrophysiology recordings (Fig. 2A). Soma of CP neurons fluorescently labeled with retrograde tracer were robustly distributed in $\mathrm{L} 5$ of both the PL and IL regions of MPFC ipsilateral to the tracer injection site (Fig. $2 \mathrm{~B}, \mathrm{C}$ ), as shown previously by us (Ferreira et al., 2015; Cheriyan et al., 2016). Using whole-cell electrophysiology in acute brain slices, we measured the intrinsic excitability of L5 CP neurons from both PL and IL cortex of sham 
and CCI mice (Fig. $2 B, C$, insets). In PL, suprathreshold recordings from $\mathrm{CP}-\mathrm{CCI}$ neurons showed a significant decrease in the frequency of APs elicited by depolarizing current steps (sham: $0.16 \pm 0.01 \mathrm{~Hz} /$ pA; CCI: $0.13 \pm 0.01 \mathrm{~Hz} / \mathrm{pA} ; p=0.039 ; t$ test; Fig. $2 D-F)$. Further analysis showed that CP-CCI neurons had a higher current threshold for AP firing (sham median: 150 pA, interquartile range: $100-150 \mathrm{pA}$; CCI median: $200 \mathrm{pA}$, interquartile range: $150-$ $200 \mathrm{pA} ; p=0.039$; Wilcoxon rank-sum test; Fig. $2 G$ ) and a lower membrane input resistance (sham: $89 \pm 4.6 \mathrm{M} \Omega$; CCI: $73 \pm$ $4.5 \mathrm{M} \Omega ; p=0.024$; Wilcoxon rank-sum test; Fig. $2 H$ ). Conversely, in IL-CP neurons, CCI had no effect on AP firing (sham: $0.14 \pm 0.01 \mathrm{~Hz} / \mathrm{pA}$; CCI: $0.17 \pm$ $0.02 \mathrm{~Hz} / \mathrm{pA} ; p=0.3$; Wilcoxon rank-sum test; Fig. 2I-K), current threshold (sham median: $150 \mathrm{pA}$, interquartile range: $100-$ $150 \mathrm{pA}$; CCI median: $100 \mathrm{pA}$, interquartile range: $100-150 \mathrm{pA} ; p=0.9$; Wilcoxon rank-sum test; Fig. $2 L$ ), or input resistance (sham: $105 \pm 8.0 \mathrm{M} \Omega$; CCI: $112 \pm 8.2$ $\mathrm{M} \Omega ; p=0.54 ; t$ test; Fig. $2 M$ ). These data show that decreases in excitability of L5 CP neurons after CCI is not uniform across different subregions of the mPFC.

\section{CP neurons in both PL and IL cortex receive weaker local excitatory inputs after nerve injury}

We next aimed to measure local excitatory circuit strength of $\mathrm{CP}$ neurons in CCI mice compared with sham controls. We targeted labeled L5 CP neurons in coronal brain slices for patch-clamp recording and synaptic input mapping using gluLSPS (see Materials and Methods). We mapped local excitatory inputs onto L5 CP neurons via photostimulation of 256 sites spanning cortical layers $1-6$ in a $16 \times 16$ square grid (Fig. $3 A, G$ ). In PL cortex, we recorded excitatory input maps from $16 \mathrm{CP}$ neurons in CCI mice and $15 \mathrm{CP}$ neurons in sham controls (Fig. 3B) and compared the data by averaging the maps and performing region-of-interest (ROI) analyses (Fig. $3 C$ ). When we pooled the excitatory maps for each group, row analysis of excitatory inputs from a defined breadth of columns (Fig. 3C, gray dashed line) revealed robust differences spanning from layer 2/3 (L2/3) to L5 (Fig. 3D). Our ROI analysis showed that local excitatory inputs originating in L2/3 (Fig. 3C, ROI 1, black line) and L5 (Fig. 3C, ROI 2, green line) were significantly weaker (L2/3: $p=0.04$; Wilcoxon rank-sum test; L5: $p=0.007, t$ test) for CCI CP neurons (L2/3: $7.9 \pm 1.5 \mathrm{pA}$; $L 5: 2.5 \pm 0.2 \mathrm{pA}$ ) compared with sham controls (L2/3: $15.5 \pm 3.5 \mathrm{pA} ; L 5: 5.0 \pm 0.9$ pA; Fig. $3 D, E)$. In IL cortex, we recorded excitatory input maps from $15 \mathrm{CP}$ neurons in CCI mice and $13 \mathrm{CP}$ neurons in sham controls (Fig. $3 H$ ). Row analysis of excitatory inputs to IL CP neurons revealed minimal decrease in excitatory input spanning from L2/3 to L5 in CCI mice (Fig. 3J). ROI analysis (Fig. 3I) showed no significant reduction in inputs originating in L2/3 (sham: $9.7 \pm 1.6$ pA; CCI: $7.0 \pm 1.7$ pA; $p=0.13$; $t$ test; Fig. $3 K$ ). However, a significant reduction in inputs originating in L5 was detected (sham: $3.0 \pm 0.3 \mathrm{pA}$; CCI: $1.8 \pm 0.4 \mathrm{pA} ; p=0.02$; test; Fig. $3 L$ ). These data show that CCI decreases the strength of local excitatory input to L5 CP neurons in both the PL and IL regions of the mPFC.

Nerve injury reduces local inhibitory input to $\mathrm{CP}$ neurons in a laminar-specific manner

Using cesium-based intracellular solution and recording at a holding potential of $+10 \mathrm{mV}$, close to the reversal potential for glutamatergic inputs, we mapped local inhibitory inputs to $\mathrm{CP}$ neurons. Inhibitory responses were elicited after stimulation (glutamate uncaging) of L2/3 and L5 for both sham and CCI-CP neurons in L5 of PL (Fig. 4A) and IL (Fig. 4G) cortex. In PL cortex, we recorded inhibitory input maps from $15 \mathrm{CP}$ neurons in CCI mice and 14 CP neurons in sham controls (Fig. 4B) and performed an ROI analysis similar to the excitatory maps (Fig. $4 C$ ). When we pooled the inhibitory maps for each group, row analysis of inputs (Fig. $4 C$, gray dashed line) to CCI -CP neurons showed weaker inhibitory responses primarily after stimulation of L2/3 (Fig. 4D). Our ROI analysis (Fig. 4C, ROI 1, black line) showed that inhibitory input resulting from $\mathrm{L} 2 / 3$ excitation was significantly weaker in CCI CP neurons (sham: $31.0 \pm 7.2 \mathrm{pA}$; CCI: $13.7 \pm 2.2 \mathrm{pA} ; p=0.04$; Wilcoxon rank-sum test; Fig. $4 E$ ). 

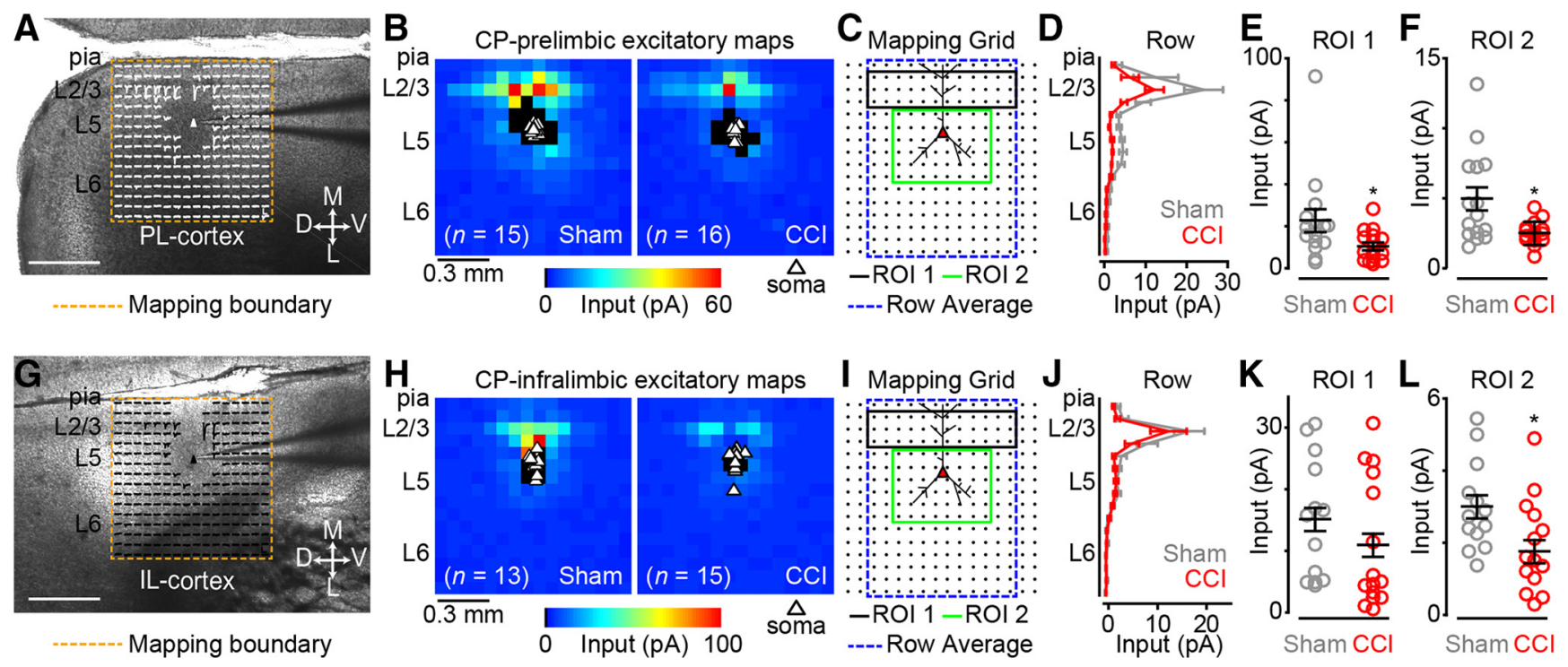

Figure 3. CP neurons of $\mathrm{CCl}$ mice have weaker excitatory input maps. $A$, Representative bright-field image depicting an excitatory trace map for a $C P$ neuron in PL cortex. Image scale bar, $500 \mu \mathrm{m}$; trace map scale bar, 50 pA/100 ms. D, Dorsal; V, ventral; M, medial; L, lateral. B, Average excitatory color maps for sham (left) and CCl (right) CP neurons in PL cortex. C, Mapping grid (16 × 16; 75 $\mu \mathrm{m}$ spacing) depicting areas of analyses; $\boldsymbol{D}$, Row average of excitatory inputs within analysis region (blue-dashed line in $\boldsymbol{C}$. $\boldsymbol{E}, \boldsymbol{F}$, Comparison of presynaptic excitatory input from R0l $1(\boldsymbol{E})$ and ROI $2(\boldsymbol{F})$ to $C P$ neurons in PL cortex. G, Representative bright-field image depicting an excitatory trace map for a (P neuron in IL cortex (right) CP neurons in IL cortex. Image scale bar, $500 \mu$ m; trace map scale bar, $50 \mathrm{pA} / 100 \mathrm{~ms}$. H, Average excitatory color maps for sham (left) and CCI (right) CP neurons in IL cortex. I, Mapping grid (16 $\times 16 ; 75 \mu \mathrm{m}$ spacing) depicting areas of ROI analyses. J, Row average of excitatory inputs within analysis region (blue-dashed line in $\boldsymbol{I}) . \boldsymbol{K}$, $\boldsymbol{L}$, Comparison of presynaptic excitatory input from ROI $1(\boldsymbol{K})$ and ROI $2(\boldsymbol{L})$ to $\left(P\right.$ neurons in IL cortex. ${ }^{*} p<0.05$.
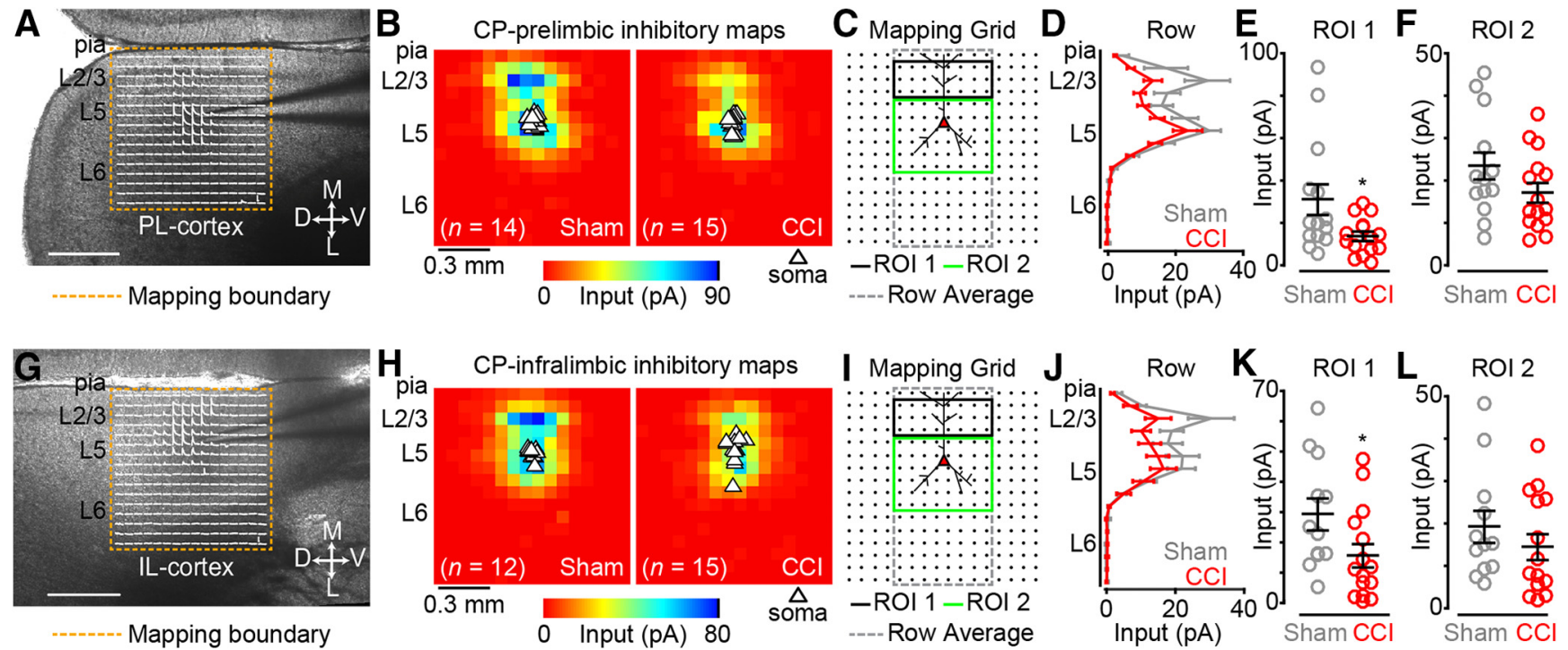

Figure 4. Inhibition driven by excitation of layer $2 / 3$ is reduced in CCI mice. $A$, Representative bright-field image depicting an inhibitory trace map for a $C P$ neuron in $P L$ cortex. Image scale bar, $500 \mu \mathrm{m}$; trace map scale bar, $150 \mathrm{pA} / 100 \mathrm{~ms}$. D, Dorsal; V, ventral; M, medial; L, lateral. B, Average inhibitory color maps for sham (left) and CCI (right) CP neurons in PL cortex. C, Mapping grid (16 $\times$ $16 ; 75 \mu \mathrm{m}$ spacing) depicting ROI analysis. $\boldsymbol{D}$, Row average of inhibitory inputs within analysis region (gray-dashed line in $\boldsymbol{C}$ ). $\boldsymbol{E}$, $\boldsymbol{F}$, Comparison of inhibitory input to PL-CP neurons after excitation of ROI $1(\boldsymbol{E})$ and ROI $2(\boldsymbol{F}) . \mathbf{G}$, Representative bright-field image depicting an inhibitory trace map for a (P neuron in IL cortex. Image scale bar, $500 \mu \mathrm{m}$; trace map scale bar, $150 \mathrm{pA} / 100 \mathrm{~ms}$. $\boldsymbol{H}$, Average inhibitory color maps for sham (left) and CCI (right) CP neurons in IL cortex.I, Mapping grid ( $16 \times 16 ; 75 \mu \mathrm{m}$ spacing) depicting ROI analysis.J, Row average of inhibitory inputs within analysis region (gray-dashed line in $\boldsymbol{I}$ ). $\boldsymbol{K}, \boldsymbol{L}$, Comparison of inhibitory input to IL-CP neurons after excitation of ROI $1(\boldsymbol{K})$ and ROI $2(\boldsymbol{L}){ }^{*} p<0.05$.

Although perisomatic inhibitory responses also appeared to be slightly weaker for CCI CP neurons, ROI analysis of L5 showed no significant differences between groups (sham: $23.4 \pm 3.1 \mathrm{pA}$; CCI: $17.1 \pm 2.3$ pA; $p=0.12$; $t$ test; Fig. $4 F)$. In IL cortex, we recorded inhibitory input maps from $15 \mathrm{CP}$ neurons in CCI mice and $12 \mathrm{CP}$ neurons in sham controls (Fig. $4 H$ ). Row analysis revealed a decrease in inhibitory input from stimulation of L2/3 in CCI CP neurons (Fig. 4J). Our ROI analysis (Fig. 4I) showed significant reduction in inhibitory inputs after $\mathrm{L} 2 / 3$ stimulation (sham: $29.2 \pm 5.3$ pA; CCI: $15.6 \pm 4.0$ pA; $p=0.04 ; t$ test; Fig.
$4 K$ ), but not after stimulation of perisomatic L5 sites (sham: $19.2 \pm 3.8 \mathrm{pA}$; CCI: $14.4 \pm 3.0 \mathrm{pA} ; p=0.2$; Wilcoxon rank-sum test; Fig. $4 L$ ). These results show both region- and laminarspecific decreases in local inhibitory input to L5 CP neurons in mPFC after CCI.

CCI effects on the photoexcitability of excitatory and inhibitory neurons in L2 and L5 of mPFC

Differences in CP maps from CCI and sham-control mice could be explained by differences in the photoexcitability of presynaptic 
A

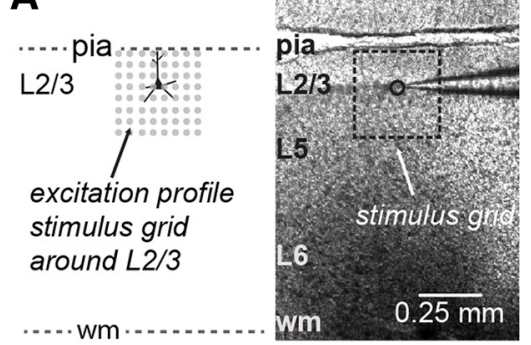

B

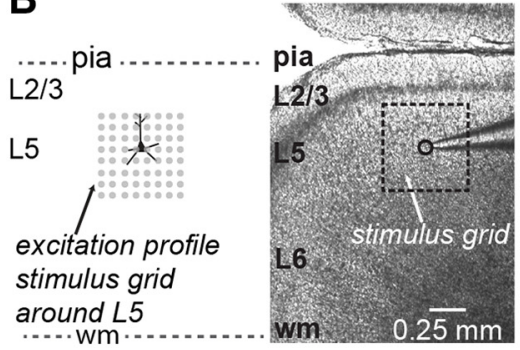

C

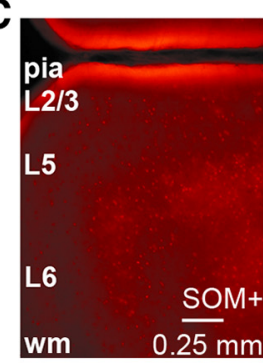

D

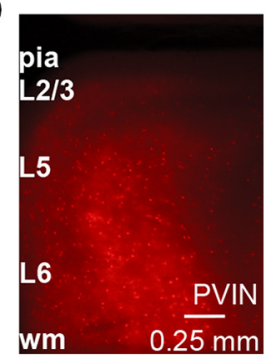

E

L2/3 Pyramidal neurons Sham

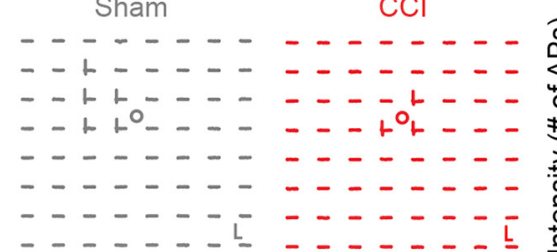

K

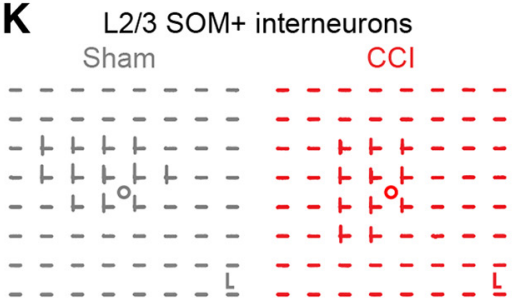

F G

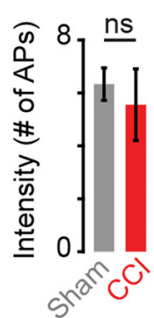

L

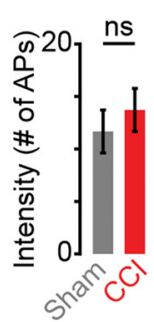

$R \quad S$

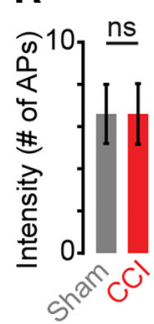

M

S
G $\quad$ H
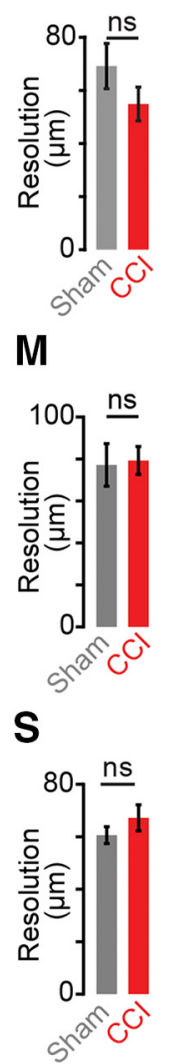

N

T
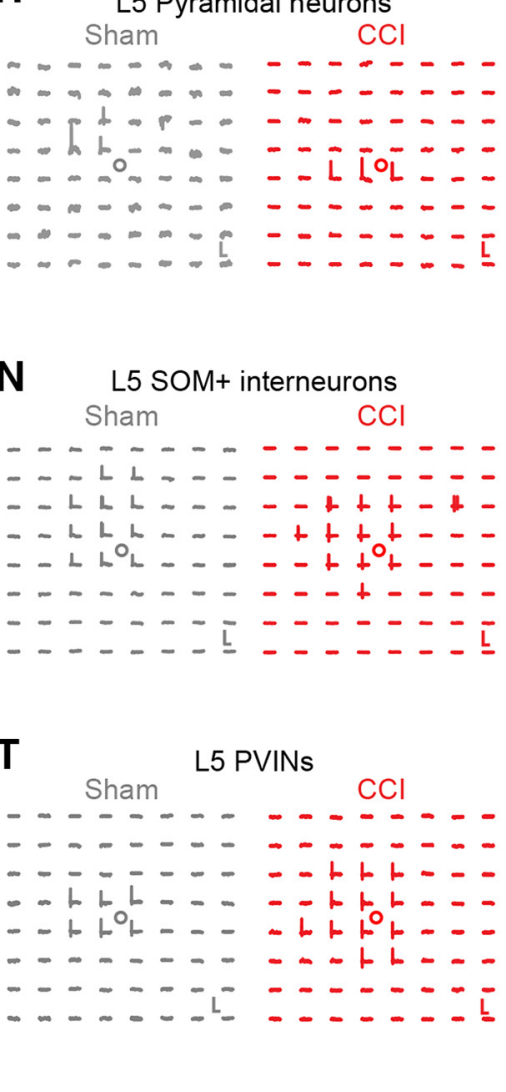

I

J
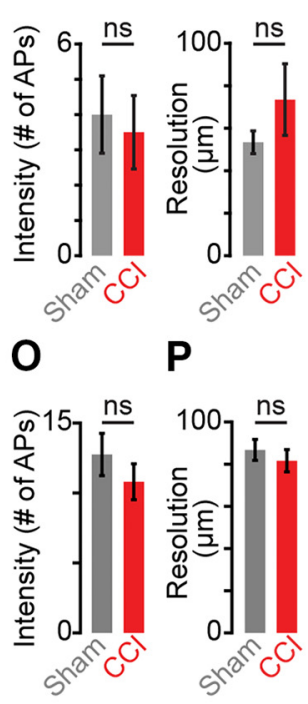

U V

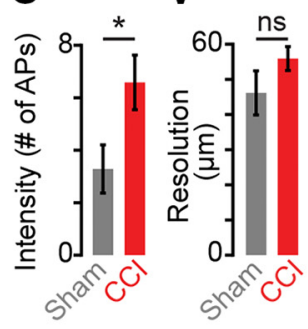

Figure 5. Excitation profiles of $L 2 / 3$ and $L 5$ neurons in $\mathrm{MPFC}$ of sham and $\mathrm{CCI}$ mice. $A$, Schematic depiction of grid orientation for EPs from $L 2 / 3$ (left) and a bright-field showing recording paradigm for excitation profiles (right). $\boldsymbol{B}$, Schematic depiction similar as in $\boldsymbol{A}$ to show recording of EPs from $L 5$ neurons. $\boldsymbol{C}, \boldsymbol{D}$, Representative fluorescent image showing distribution of $S 0 \mathrm{M}+$ neurons $(\boldsymbol{C})$ and PVINs (D) in PL cortex. $\boldsymbol{E}$, Examples of EPs from L2/3 pyramidal neurons for sham (left) and CCI (right). Scale bar, $5 \mathrm{mV}, 100 \mathrm{~ms}$. $\boldsymbol{F}, \boldsymbol{G}$, Intensity ( $\boldsymbol{F}$ ) and resolution $(\boldsymbol{G})$ of photoexcitability in L2/3 neurons $($ sham $=6, C \mathrm{Cl}=9)$. $\boldsymbol{H}$, Examples of EPs from $L 5$ pyramidal neurons. Scale bar, $2.5 \mathrm{mV}, 100 \mathrm{~ms}$. $\boldsymbol{I}, \boldsymbol{J}$, Intensity $(\boldsymbol{I})$ and resolution $(\boldsymbol{J})$ of photoexcitability of $L 5$ neurons $($ sham $=6, C(\mathrm{Cl}=4) . \boldsymbol{K}$, Examples of EPs of L2/3 SOM + interneurons. Scale bar, $5 \mathrm{mV}, 100 \mathrm{~ms} . \boldsymbol{L}, \boldsymbol{M}$, Intensity $(\boldsymbol{L})$ and resolution $(\boldsymbol{M})$ of EPs of L2/3 SOM + neurons (sham $=6, C C \mathrm{Cl}=7)$. $\boldsymbol{N}$, Examples of EPs for $\mathrm{L} 5 \mathrm{SOM}+$

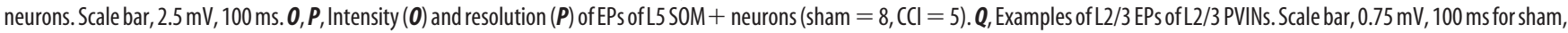
$0.5 \mathrm{mV}, 100 \mathrm{~ms}$ for CCl. $\boldsymbol{R}, \boldsymbol{S}$, Intensity $(\boldsymbol{R})$ and resolution $(\boldsymbol{S})$ of EPs from L2/3 PVIN neurons (sham = 5, CCl = 5). $\boldsymbol{T}$, Example EPs for L5 PVINs mice. Scale bar, $2.5 \mathrm{mV}, 100 \mathrm{~ms}$ for sham and $1 \mathrm{mV}, 100$ ms for CCI. $\boldsymbol{U}, \boldsymbol{V}$, Intensity $(\boldsymbol{U})$ and resolution $(\boldsymbol{V})$ of EPs in L5 PVINs (sham $=7, \mathrm{CCl}=12) .{ }^{*} p<0.05$.

neurons rather than differences in synaptic connectivity. To explore this possibility, we performed excitation profiles (EPs), maps revealing the number and spatial distribution of photoexcitable sites across individual neurons, to measure photoexcitability of presynaptic neurons quantitatively as described previously (Wood and Shepherd, 2010). We obtained EPs in slices from sham and CCI animals by recording neurons in loose seal mode and mapping their photoexcitability under the same conditions used for synaptic input mapping. We recorded EPs for both excitatory and inhibitory neurons in L2/3 (Fig. 5A) and L5 (Fig. 5B), which comprise the main presynaptic source of local inputs to CP neurons. Transgenic strategies (see Materials and Methods) were used to identify SOM + and PVINs by expres- sion of red fluorescent protein Td-Tomato (Fig. 5C,D). The EP datasets were analyzed to determine the mean distance of spike evoking sites from the soma as an estimator of the resolution of photostimulation and the total number of spikes per map per cell, an estimator of photoexcitability. We found that photoexcitability of pyramidal and SOM + neurons in L2/3 and L5 was not significantly different between sham and CCI animals (Fig. $5 E-P$, Table 1). Similarly, CCI did not alter the photoexcitability of L2/3 PVIN neurons (Fig. 5Q-S, Table 1). However, we did find that the photoexcitability of L5 PV+ neurons was significantly enhanced in CCI animals as evident by increase in the total number of spikes (sham: $3.3 \pm 0.9$; CCI: $6.6 \pm 1.0 ; p=0.047 ; t$ test) without a significant change in resolution of photoexcitable sites (Fig. $5 T-V$ ). 
Table 1. CCl effects on photoexcitability

\begin{tabular}{|c|c|c|c|c|c|c|}
\hline \multirow[b]{2}{*}{ Cell type } & \multicolumn{3}{|c|}{ Total no. of spikes } & \multicolumn{3}{|c|}{ Photoexcitation resolution $(\mu \mathrm{m})$} \\
\hline & Sham & $\mathrm{CCl}$ & $p$-value & Sham & $\mathrm{CCl}$ & $p$-value \\
\hline L2 pyramidal & $6.3 \pm 0.6$ & $5.6 \pm 1.35$ & 0.7 & $54.9 \pm 6.4$ & $69.2 \pm 8.5$ & 0.2 \\
\hline L5 pyramidal & $3.8 \pm 0.9$ & $3.5 \pm 1.0$ & 0.8 & $52.8 \pm 4.4$ & $73.5 \pm 16.9$ & 0.2 \\
\hline L2 SOM+ & $11.7 \pm 2.1$ & $13.7 \pm 2.0$ & 0.5 & $77.2 \pm 10.1$ & $79.3 \pm 6.7$ & 0.9 \\
\hline L5 SOM+ & $12.8 \pm 1.3$ & $10.8 \pm 1.5$ & 0.4 & $81.6 \pm 5.0$ & $86.8 \pm 5.3$ & 0.5 \\
\hline L2 PVIN & $6.6 \pm 1.4$ & $6.6 \pm 1.43$ & 1.0 & $60.6 \pm 3.2$ & $67.2 \pm 5.0$ & 0.3 \\
\hline L5 PVIN & $3.3 \pm 1.0$ & $6.6 \pm 1.0$ & 0.047 & $46.1 \pm 6.3$ & $56.0 \pm 3.4$ & 0.2 \\
\hline
\end{tabular}

Data are shown as mean \pm SEM. Statistical significance of all data was determined using Student's unpaired $t$ test. Statistically significant value is displayed in bold.

CCI shifts the inhibitory/excitatory (I/E) ratio in local circuits of CP neurons

We next analyzed whether CCI induces a shift in the I/E balance of local inputs originating from specific laminar locations. For this, we took the ratio of the mean input values for inhibitory (green dashed line) and the excitatory (black line) ROIs used for L2/3 (Fig. 6A) and L5 (Fig. 6D) analysis of local circuit maps (Figs. 3,4 ). We found that the I/E ratio of L2/3 inputs to PL-CP neurons was unaltered in CCI mice due to similar reductions in both excitatory and inhibitory input (sham: $1.49 \pm 0.05, \mathrm{CCI}$ : $1.45 \pm 0.02 ; p=0.47$; $t$ test; Fig. $6 B$ ). However, the $\mathrm{I} / \mathrm{E}$ ratio of $\mathrm{L} 2 / 3$ inputs to IL-CP neurons was significantly reduced in CCI mice (sham: $2.3 \pm 0.09$, CCI: $1.85 \pm 0.05 ; p=0.002$; Wilcoxon rank-sum test; Fig. $6 C$ ). This is likely due to a significant decrease in inhibitory input, but not excitatory input, following L2/3 stimulation (Figs. $3 K, 4 K$ ). The I/E ratio of L5 inputs to PL-CP neurons in CCI mice was significantly increased (sham: $2.2 \pm 0.1$, CCI: $2.8 \pm 0.07, p=2.6 \times 10^{-5}$; $t$ test; Fig. $\left.6 E\right)$, whereas it was significantly decreased for IL-CP neurons in CCI (sham: $2.93 \pm$ 0.1 , CCI: $2.0 \pm 0.08 ; p=1.3 \times 10^{-6}$; $t$ test; Fig. $6 F$ ). The PL-IL dichotomy in I/E shifts induced by CCI reflects the differential decreases to excitatory and inhibitory input following L5 stimulation observed in our mapping data (Figs. $3 L, 4 L$ ). Overall, these data suggest that CCI shifts the laminar I/E balance of local CP circuits differentially in PL and IL.

\section{CCI reduces the excitability and local inhibitory inputs of PL-CP neurons ipsilateral to nerve injury}

We next tested whether CCI decreases excitability of CP neurons in PL cortex ipsilateral to the injured hindpaw. For this, we injected retrograde tracer into the left PAG, which was ipsilateral to CCI of the left sciatic nerve (Fig. $7 A, B$ ). Interestingly, suprathreshold recordings from ipsilateral CP-CCI neurons (sham: 7 neurons; CCI: 8 neurons) showed increased current threshold for AP firing (sham median: $150 \mathrm{pA}$, interquartile range: 137.5-162.5 pA; CCI median: 250 pA, interquartile range: $200-250 \mathrm{pA} ; p=$ 0.014 ; $t$ test; Fig. $7 C, D$ ). However, the frequency of APs elicited by depolarizing current steps was unchanged by CCI (sham: $0.10 \pm$ $0.01 \mathrm{~Hz} / \mathrm{pA}$; CCI: $0.10 \pm 0.01 \mathrm{~Hz} / \mathrm{pA} ; p=0.98$; $t$ test; Fig. $7 E$ ). Further analyses showed that CP-CCI neurons ipsilateral to CCI have a lower membrane input resistance (sham: $87 \pm 6.0 \mathrm{M} \Omega$; CCI: $66 \pm 5.8 \mathrm{M} \Omega ; p=0.023$; $t$ test; Fig. $7 F)$ and a narrower AP half-width (sham: $0.84 \pm 0.018 \mathrm{~ms}$; CCI: $0.62 \pm 0.005 \mathrm{~ms} ; p=$ 0.031 ; $t$ test; Fig. $7 G$ ). Overall, this shows that unilateral CCI can decrease input resistance and increase current threshold for AP firing of CP neurons bilaterally across PL cortex.

Using glu-LSPS, we also recorded local excitatory and inhibitory input maps from PL-CP neurons ( $\operatorname{cham:~} n=8$; CCI: $n=10$ ) ipsilateral to CCI (Fig. $8 A, F$ ). Row average analysis (Fig. $8 B$, blue dashed line) showed that excitatory inputs are unaltered across L2/3 and L5 between CCI and sham (Fig. 8C). ROI analyses (Fig.
$8 B$, ROI 1, black line, ROI 2, green line) showed no significant differences in excitatory inputs from $\mathrm{L} 2 / 3$ ( $\mathrm{CCI}=7.0 \pm 1.7 ; p=0.9 ; t$ test; Fig. $8 D)$ or L5 $($ sham $=1.1 \pm 0.2$; $\mathrm{CCI}=1.0 \pm 0.3 ; p=0.66$; $t$ test; Fig. $8 E$ ) between sham and CCI. Next, we analyzed the inhibitory input maps from the same PL-CP neurons (Fig. 8F). Row average analyses (Fig. 8G, gray dashed line) showed weaker inhibitory responses after stimulation of L2/3 and L5 in PL-CP neurons of CCI mice (Fig. 8 H). ROI analyses showed a significant reduction in inhibitory inputs to PL-CP neurons after L2/3 stimulation ( sham $=21.4 \pm 3.1$; $\mathrm{CCI}=13.6 \pm 1.9 ; p=0.041 ; t$ test; Fig. $8 I$ ), but not L5 stimulation $($ sham $=19.9 \pm 2.7 ; \mathrm{CCI}=12.9 \pm 3.4 ; p=0.014 ; t$ test; Fig. $8 J$ ), in CCI mice. These results indicate that CCI bilaterally attenuates local inhibitory inputs to L5 PL-CP neurons in a laminarspecific manner.

\section{Discussion}

Here, we report that peripheral nerve injury producing neuropathic pain behavior alters both excitability and local circuit phenotypes of L5 pyramidal neurons in MPFC that send projections to the PAG. The PAG is a key midbrain structure within the descending network responsible for inhibiting ascending nociceptive input (Basbaum and Fields, 1978; Behbehani, 1995; Millan, 2002; Benarroch, 2012). Our findings here suggest that nerve injury induces dysfunction in cortical circuits directly upstream of the PAG, which likely alters homeostasis of endogenous pain modulation, potentially contributing to the persistence of chronic pain.

\section{Functional roles of $\mathrm{PL}$ and IL cortex in pain}

$\mathrm{PL}$ and IL cortex are adjacent $\mathrm{mPFC}$ regions that play opposing roles in fear learning (Vidal-Gonzalez et al., 2006; Laurent and Westbrook, 2009; Sierra-Mercado et al., 2011). However, studies indicate that PL cortex plays a more prominent role than IL cortex in pain processing. Lesions of PL cortex before inducing peripheral inflammation blocks emergence of hyperalgesia and conditioned-place aversion, whereas lesions of IL cortex does not (Jiang et al., 2014; Wang et al., 2015). Our data show that CCI reduces intrinsic excitability of PL-CP neurons but not IL-CP neurons. We also demonstrate that CCI enhances the I/E balance of local L5 input to PL-CP neurons. These data are consistent with evidence showing that deactivation of PL cortex contributes to chronic pain. For example, activating PL cortex reduces allodynia and affective symptoms produced by nerve injury (Millecamps et al., 2007; Lee et al., 2015). Blocking glutamatergic transmission in nucleus accumbens (NAc) reduces, but does not eliminate, pain relief driven by PL stimulation (Lee et al., 2015). This suggests that attenuated PL-NAc activity contributes to chronic pain, but that other mechanisms may be involved. Given that the PAG is involved in endogenous analgesia, we speculate that diminished activity of the PL-PAG pathway also contribute to the persistence of chronic pain after nerve injury. Future strategies aimed at activating the PL-PAG pathway in chronic pain models are needed to confirm this.

Although a role of IL cortex in pain is emerging, it remains unclear. Whereas we show that CCI does not affect intrinsic excitability of IL-CP neurons, circuit-mapping data reveal decreases to local I/E balance of both L2 and L5 inputs, suggesting that chronic pain increases local activity of the IL-PAG pathway. This is consistent with a study showing glutamate stimulation of IL cortex enhances nociception via metabotropic glutamate receptor 5 activity (David-Pereira et al., 2016). This infers that the functional roles of PL and IL cortex in descending modulation are distinct. Descending anti-nociceptive action of the PAG is medi- 
ated through the rostral ventromedial medulla (RVM) (Vanegas et al., 1984; Aimone and Gebhart, 1986; Cheng et al., 1986; Morgan et al., 1992). However, activation of this same supraspinal circuity can also facilitate nociceptive signals (Light et al., 1986; Fields, 1992; Urban and Gebhart, 1999; Porreca et al., 2002). This infers that distinct circuits within the mPFCPAG-RVM network modulate suppression and facilitation of pain input. Distinct outputs from PL and IL targeting different subpopulations of PAG neurons may contribute to this dichotomy.

\section{Reduction in local excitatory circuit strength of CP neurons after CCI}

We are the first to show that layer $2 / 3$ (L2/3) excitatory input to CP neurons, the predominant local input to CP neurons (Ferreira et al., 2015), is significantly decreased $7 \mathrm{~d}$ after CCI. Previous pain studies report conflicting changes to $\mathrm{L} 2 / 3$ neurons in mPFC. A specific subtype of L2/3 pyramidal neurons in anterior cingulate cortex (ACC) are hyperexcitable after nerve injury (Cao et al., 2009). Intrinsic excitability of $\mathrm{L} 2 / 3$ neurons in PL cortex is reduced $1 \mathrm{~d}$ after the onset of inflammatory pain (Wang et al., 2015). Another study did not observe any significant changes to intrinsic excitability of L2/3 neurons in PL cortex after nerve injury (Metz et al., 2009). We show that photoexcitability of L2/3 pyramidal neurons $7 \mathrm{~d}$ after CCI is unchanged. Therefore, we interpret reduced $\mathrm{L} 2 / 3$ excitation of L5 CP neurons as a decrease in input strength and/or number of inputs. Recent work shows that neuropathic pain decreases glutamatergic transmission to L5 pyramidal neurons in PL cortex (Kelly et al., 2016), which, based on our excitatory mapping data, is due at least in part to diminished local excitatory input.

\section{Laminar-specific effects of CCI on local} inhibitory circuits of CP neurons

We show that CCI decreases local inhibitory inputs to CP neurons after stimulation of $\mathrm{L} 2 / 3$. This is possibly due to CCI attenuating direct inhibition of L5 CP neurons by $\mathrm{L} 2 / 3$ inhibitory neurons (Jiang et al., 2013; Naka and Adesnik, 2016). Alternatively, CCI may alter an interlaminar disynaptic pathway. Across cortex, SOM + L5 inhibitory neurons, also called Martinotti cells, play a key role in L2/3 feedforward inhibition of L5 pyramidal neurons (Kapfer et al., 2007; Otsuka and Kawaguchi, 2009; Apicella et al., 2012; Jiang et al., 2015; Naka and Adesnik, 2016). We show that photoexcitability of both L2/3 and L5 SOM + cells is not altered by CCI, demonstrating that decreases in local inhibitory inputs are not due to
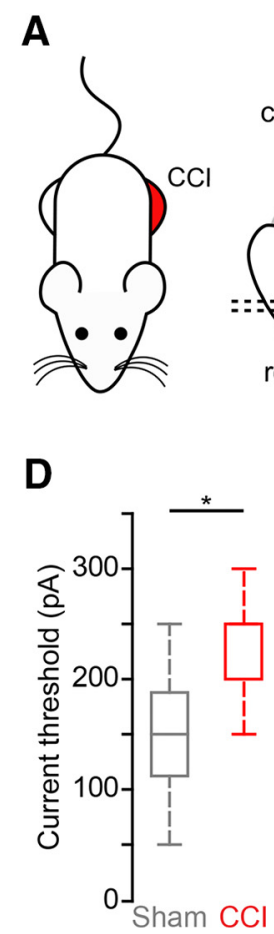
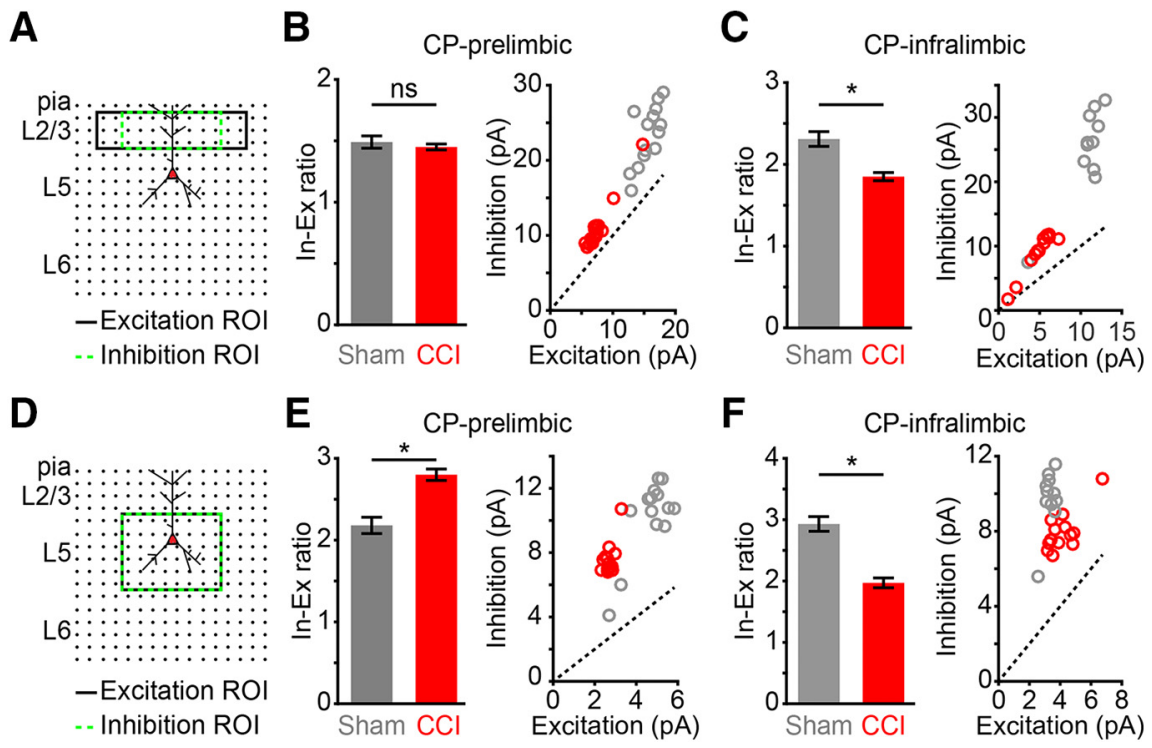

Figure 6. Region-specific alterations to local I/Ebalance in CCI mice. $\boldsymbol{A}$, Mapping grid ( $16 \times 16 ; 75 \mu \mathrm{m}$ spacing) depicting areas of analysis for mean excitatory (black line) and inhibitory (green dashed line) input after L2/3 excitation. $\boldsymbol{B}, \boldsymbol{C}$, Bar graph of mean I/E ratio (left) and scatter plot of excitatory and inhibitory input (right) for L2/3 input to CP neurons in PL cortex (B) and IL cortex (C) of sham and CCI mice. ${ }^{*} p<0.05$. D, Mapping grid ( $16 \times 16 ; 75 \mu \mathrm{m}$ spacing) depicting areas of analysis for mean excitatory (black line) and inhibitory (green dashed line) input after $L 5$ excitation. $\boldsymbol{E}, \boldsymbol{F}$, Bar graph of mean I/E ratio (left) and scatter plot of excitatory and inhibitory input (right) for L5 input to CP neurons in PL cortex $(\boldsymbol{E})$ and IL cortex $(\boldsymbol{F})$ of sham and CCI mice. * $p<0.05$.
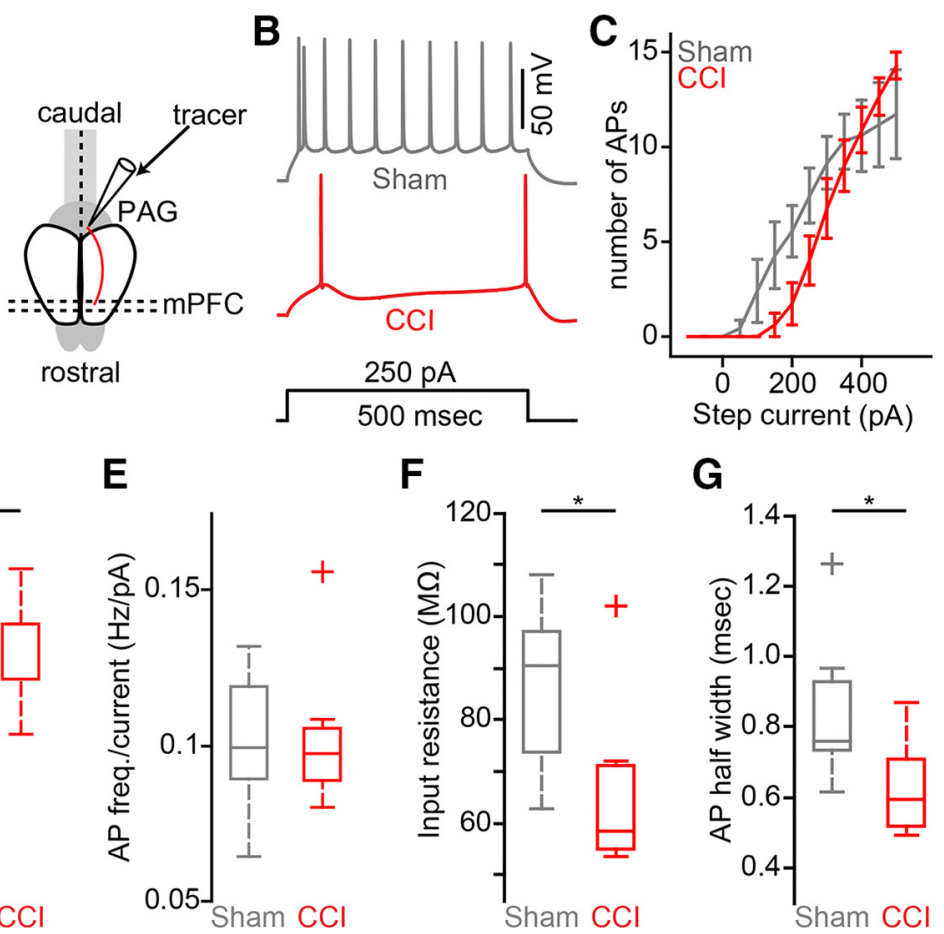

Figure 7. Reduced excitability of CP neurons in PL ipsilateral to CCI. $A$, Schematic showing retrograde tracer injection to $P A G$ ipsilateral to $C C I$. $\boldsymbol{B}$, Representative traces showing AP spikes generated in ipsilateral $C P$ neurons in sham and $C C I$ to a $250 \mathrm{pA}$ current step. $\boldsymbol{C}$, Example traces of current-evoked action potential firing from a $\mathrm{CP}$ neuron in sham (gray) and $\mathrm{CCl}$ (red) in prelimbic cortex ipsilateral to $\mathrm{CCl}$. Scale bar, $50 \mathrm{mV}$. $\boldsymbol{D}-\boldsymbol{G}$, Current threshold $(\boldsymbol{D})$, input resistance $(\boldsymbol{E})$, AP height $(\boldsymbol{F})$, and AP half-width $(\boldsymbol{G})$ comparisons for sham $(n=7)$ and $\mathrm{CCl}-\mathrm{CP}(n=9)$ neurons. ${ }^{*} p<0.05$.

attenuated SOM+ excitability. Given that we observed decreased L2/3 excitatory input to L5 CP neurons after CCI, L2/3 excitation of L5 SOM+ neurons may also be attenuated, leading to decreased feedforward inhibition of L5 CP neurons. However, with the reduction of L5 excitatory input, the local I/E balance of L5 

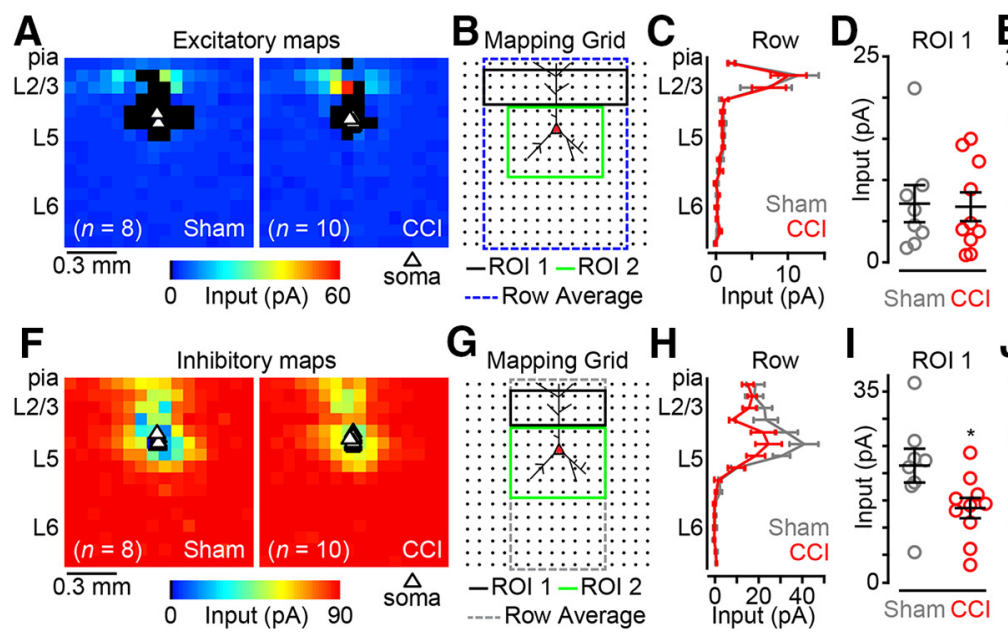

Figure 8. Inhibition driven by excitation of layer $2 / 3$ is reduced in PL-CP neurons ipsilateral to nerve injury. $A$, Average excitatory color maps for sham $(n=8)$ and $C \mathrm{CI}(n=10)$ PL-CP neurons ipsilateral to nerve injury. $\boldsymbol{B}$, Mapping grid $(16 \times 16 ; 75 \mu \mathrm{m} \mathrm{spacing})$ depicting ROI analyses areas for excitatory maps. $\boldsymbol{C}$, Row average of excitatory inputs within analysis region (blue-dashed line in $\boldsymbol{B}$ ). $\boldsymbol{D}, \boldsymbol{E}$, Comparison of excitatory inputs from ROI 1 (D) and ROI 2 (E). $\boldsymbol{F}$, Average inhibitory color maps for PL-CP neurons ipsilateral to nerve injury. G, Mapping grid ( $16 \times 16 ; 75 \mu \mathrm{m}$ spacing) depicting ROI analyses areas for inhibitory input maps. $\boldsymbol{H}$, Row average of inhibitory inputs within analysis region (gray-dashed line in G).I,J, Comparison of inhibitory inputs following excitation of ROI 1 (I) and $\mathrm{ROI} 2(\boldsymbol{J}) .{ }^{*} p<0.05$.

input is still increased, likely decreasing overall activation of PL-CP neurons.

Previous pain studies report alterations to L5 inhibitory pathways in mPFC. In ACC, reciprocal connectivity between L5 pyramidal neurons and L5 fast-spiking inhibitory neurons is reduced after nerve injury (Blom et al., 2014). Arthritic pain causes cognitive deficits resulting from hyperactivity of the basolateral amygdala (BLA) driving polysynaptic inhibition of L5 pyramidal neurons in PL cortex (Ji et al., 2010). Similarly, nerve injury increases input to PVINs in PL cortex, thus decreasing the excitability of L5 pyramidal neurons (Zhang et al., 2015). Interestingly, our mapping data show that CCI does not alter L5 inhibitory input to PL-CP neurons. One explanation for this is that increased PVIN inhibition of L5 pyramidal neurons after nerve injury (Zhang et al., 2015) is driven by long-range glutamatergic inputs to PVINs, whereas our input maps are local and do not activate long-range inputs. Another explanation is that CCI does not affect the sensitivity of PVINs to uncaged glutamate. However, we found that CCI increases the sensitivity of L5 PVINs to glutamate uncaging. Importantly, our circuit mapping nonselectively activated all classes of inhibitory interneurons. Previous work shows that PVINs and SOM+ neurons differentially target cortical pyramidal neurons based on projection target (Lee et al., 2014; Rock and Apicella, 2015; McGarry and Carter, 2016). Therefore, if L5 PVINs do not robustly target CP neurons, then increased sensitivity of L5 PVINs to glutamate uncaging after CCI may not lead to measurable changes in L5 inhibitory input to CP neurons. Nonetheless, future studies determining connectivity of PVIN and SOM+ neurons to CP neurons and measuring local circuit strength of PVINs and SOM + neurons after nerve injury are critical for illuminating the mechanisms underlying our observed decreases in local inhibitory input to CP neurons.

\section{Bilateral alterations to $\mathrm{CP}$ neurons after unilateral CCI}

Unilateral nerve injury can evoke bilateral pain behavior (Seltzer et al., 1990; Vos et al., 1994; Sinnott et al., 1999). Here, we report that unilateral CCI reduces intrinsic excitability of CP neurons bilaterally in PL cortex. This suggests that CCI attenuates cortical
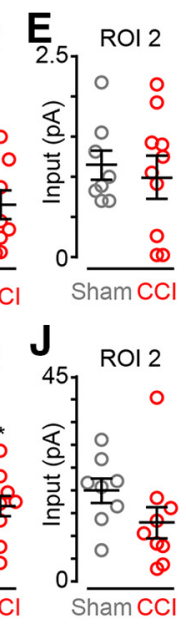

input to both hemispheres of the PAG, which could contribute to bilateral sensitization. Interestingly, CCI did not alter local excitatory circuit strength of PL-CP neurons ipsilateral to injury, but did reduce local inhibitory inputs evoked by stimulation of L2/3. This laminar-specific reduction of inhibitory input is similar for $\mathrm{CP}$ neurons in both PL hemispheres. It is probable that increased BLA input to mPFC caused by chronic pain (Ji et al., 2010; Zhang et al., 2015) is bilaterally altering local inhibitory neurons in PL cortex. The optogenetic strategies that we used (Cheriyan et al., 2016) can be used in future studies to determine whether CCI alters contralateral BLA input to inhibitory neurons in $\mathrm{mPFC}$.

Implications for CP circuit dysfunction The CNS contains a descending modulatory network that drives endogenous pain relief (Basbaum and Fields, 1978; Stamford, 1995). Analgesic mechanisms of this network involve activation of the PAG via opioid or cannabinoid pathways (Morgan et al., 1991; Morgan et al., 1992; Lichtman et al., 1996). It is believed that mPFC activity triggers opioid release in PAG, which contributes to endogenous analgesia (Wager et al., 2004; Tracey and Mantyh, 2007). We demonstrate that CCI alters the I/E balance of local inputs to mPFC neurons directly upstream of the PAG. These data are consistent with the implication that disruption of the descending analgesic network contributes to the pathology of chronic pain (Ossipov et al., 2010; van Wijk and Veldhuijzen, 2010). Future work aimed at determining the impact of mPFC input on PAG circuits is necessary to reveal a functional role of the mPFC-PAG pathway in chronic pain pathology.

\section{References}

Aimone LD, Gebhart GF (1986) Stimulation-produced spinal inhibition from the midbrain in the rat is mediated by an excitatory amino acid neurotransmitter in the medial medulla. J Neurosci 6:1803-1813. CrossRef Medline

Alvarado S, Tajerian M, Millecamps M, Suderman M, Stone LS, Szyf M (2013) Peripheral nerve injury is accompanied by chronic transcriptomewide changes in the mouse prefrontal cortex. Mol Pain 9:21. CrossRef Medline

Alvarado S, Tajerian M, Suderman M, Machnes Z, Pierfelice S, Millecamps M, Stone LS, Szyf M (2015) An epigenetic hypothesis for the genomic memory of pain. Front Cell Neurosci 9:88. CrossRef Medline

Anderson CT, Sheets PL, Kiritani T, Shepherd GM (2010) Sublayer-specific microcircuits of corticospinal and corticostriatal neurons in motor cortex. Nat Neurosci 13:739-744. CrossRef Medline

Apicella AJ, Wickersham IR, Seung HS, Shepherd GM (2012) Laminarly orthogonal excitation of fast-spiking and low-threshold-spiking interneurons in mouse motor cortex. J Neurosci 32:7021-7033. CrossRef Medline

Apkarian AV (2004) Cortical pathophysiology of chronic pain. Novartis Found Symp 261:239-245; discussion 245-261. Medline

Apkarian AV, Sosa Y, Sonty S, Levy RM, Harden RN, Parrish TB, Gitelman DR (2004) Chronic back pain is associated with decreased prefrontal and thalamic gray matter density. J Neurosci 24:10410-10415. CrossRef Medline

Baliki MN, Chialvo DR, Geha PY, Levy RM, Harden RN, Parrish TB, Apkarian AV (2006) Chronic pain and the emotional brain: specific brain activity associated with spontaneous fluctuations of intensity of chronic back pain. J Neurosci 26:12165-12173. CrossRef Medline 
Basbaum AI, Fields HL (1978) Endogenous pain control mechanisms: review and hypothesis. Ann Neurol 4:451-462. CrossRef Medline

Behbehani MM (1995) Functional characteristics of the midbrain periaqueductal gray. Prog Neurobiol 46:575-605. CrossRef Medline

Benarroch EE (2012) Periaqueductal gray: an interface for behavioral control. Neurology 78:210-217. CrossRef Medline

Blom SM, Pfister JP, Santello M, Senn W, Nevian T (2014) Nerve injuryinduced neuropathic pain causes disinhibition of the anterior cingulate cortex. J Neurosci 34:5754-5764. CrossRef Medline

Bonin RP, Bories C, De Koninck Y (2014) A simplified up-down method (SUDO) for measuring mechanical nociception in rodents using von frey filaments. Mol Pain 10:26. CrossRef Medline

Bushnell MC, Ceko M, Low LA (2013) Cognitive and emotional control of pain and its disruption in chronic pain. Nat Rev Neurosci 14:502-511. CrossRef Medline

Cao XY, Xu H, Wu LJ, Li XY, Chen T, Zhuo M (2009) Characterization of intrinsic properties of cingulate pyramidal neurons in adult mice after nerve injury. Mol Pain 5:73. CrossRef Medline

Cardoso-Cruz H, Lima D, Galhardo V (2013) Impaired spatial memory performance in a rat model of neuropathic pain is associated with reduced hippocampus-prefrontal cortex connectivity. J Neurosci 33:2465-2480. CrossRef Medline

Chaplan SR, Bach FW, Pogrel JW, Chung JM, Yaksh TL (1994) Quantitative assessment of tactile allodynia in the rat paw. J Neurosci Methods 53:5563. CrossRef Medline

Cheng ZF, Fields HL, Heinricher MM (1986) Morphine microinjected into the periaqueductal gray has differential effects on 3 classes of medullary neurons. Brain Res 375:57-65. CrossRef Medline

Cheriyan J, Kaushik MK, Ferreira AN, Sheets PL (2016) Specific targeting of the basolateral amygdala to projectionally defined pyramidal neurons in prelimbic and infralimbic cortex. eNeuro 3:ENEURO.0002-16.2016. CrossRef Medline

Cordeiro Matos S, Zhang Z, Séguéla P (2015) Peripheral neuropathy induces HCN channel dysfunction in pyramidal neurons of the medial prefrontal cortex. J Neurosci 35:13244-13256. CrossRef Medline

David-Pereira A, Puga S, Gonçalves S, Amorim D, Silva C, Pertovaara A, Almeida A, Pinto-Ribeiro F (2016) Metabotropic glutamate 5 receptor in the infralimbic cortex contributes to descending pain facilitation in healthy and arthritic animals. Neuroscience 312:108-119. CrossRef Medline

Derbyshire SW, Jones AK, Collins M, Feinmann C, Harris M (1999) Cerebral responses to pain in patients suffering acute post-dental extraction pain measured by positron emission tomography (PET). Eur J Pain 3:103-113. CrossRef Medline

Ferreira AN, Yousuf H, Dalton S, Sheets PL (2015) Highly differentiated cellular and circuit properties of infralimbic pyramidal neurons projecting to the periaqueductal gray and amygdala. Front Cell Neurosci 9:161. CrossRef Medline

Fields HL (1992) Is there a facilitating component to central pain modulation? Am Pain Soc J 1:71-78.

Floyd NS, Price JL, Ferry AT, Keay KA, Bandler R (2000) Orbitomedial prefrontal cortical projections to distinct longitudinal columns of the periaqueductal gray in the rat. J Comp Neurol 422:556-578. CrossRef Medline

Gabbott PL, Warner TA, Jays PR, Salway P, Busby SJ (2005) Prefrontal cortex in the rat: projections to subcortical autonomic, motor, and limbic centers. J Comp Neurol 492:145-177. CrossRef Medline

Hardy SG (1985) Analgesia elicited by prefrontal stimulation. Brain Res 339:281-284. CrossRef Medline

Hardy SG, Haigler HJ (1985) Prefrontal influences upon the midbrain: a possible route for pain modulation. Brain Res 339:285-293. CrossRef Medline

Ji G, Sun H, Fu Y, Li Z, Pais-Vieira M, Galhardo V, Neugebauer V (2010) Cognitive impairment in pain through amygdala-driven prefrontal cortical deactivation. J Neurosci 30:5451-5464. CrossRef Medline

Jiang X, Wang G, Lee AJ, Stornetta RL, Zhu JJ (2013) The organization of two new cortical interneuronal circuits. Nat Neurosci 16:210-218. CrossRef Medline

Jiang X, Shen S, Cadwell CR, Berens P, Sinz F, Ecker AS, Patel S, Tolias AS (2015) Principles of connectivity among morphologically defined cell types in adult neocortex. Science 350:aac9462. CrossRef Medline

Jiang ZC, Pan Q, Zheng C, Deng XF, Wang JY, Luo F (2014) Inactivation of the prelimbic rather than infralimbic cortex impairs acquisition and expression of formalin-induced conditioned place avoidance. Neurosci Lett 569:89-93. CrossRef Medline

Jones AK, Derbyshire SW (1997) Reduced cortical responses to noxious heat in patients with rheumatoid arthritis. Ann Rheum Dis 56:601-607. CrossRef Medline

Kapfer C, Glickfeld LL, Atallah BV, Scanziani M (2007) Supralinear increase of recurrent inhibition during sparse activity in the somatosensory cortex. Nat Neurosci 10:743-753. CrossRef Medline

Kelly CJ, Huang M, Meltzer H, Martina M (2016) Reduced glutamatergic currents and dendritic branching of layer 5 pyramidal cells contribute to medial prefrontal cortex deactivation in a rat model of neuropathic pain. Front Cell Neurosci 10:133. CrossRef Medline

Kiritoshi T, Ji G, Neugebauer V (2016) Rescue of impaired mGluR5-driven endocannabinoid signaling restores prefrontal cortical output to inhibit pain in arthritic rats. J Neurosci 36:837-850. CrossRef Medline

Laurent V, Westbrook RF (2009) Inactivation of the infralimbic but not the prelimbic cortex impairs consolidation and retrieval of fear extinction. Learn Mem 16:520-529. CrossRef Medline

Lee AT, Gee SM, Vogt D, Patel T, Rubenstein JL, Sohal VS (2014) Pyramidal neurons in prefrontal cortex receive subtype-specific forms of excitation and inhibition. Neuron 81:61-68. CrossRef Medline

Lee M, Manders TR, Eberle SE, Su C, D'amour J, Yang R, Lin HY, Deisseroth K, Froemke RC, Wang J (2015) Activation of corticostriatal circuitry relieves chronic neuropathic pain. J Neurosci 35:5247-5259. CrossRef Medline

Lichtman AH, Cook SA, Martin BR (1996) Investigation of brain sites mediating cannabinoid-induced antinociception in rats: evidence supporting periaqueductal gray involvement. J Pharmacol Exp Ther 276:585-593. Medline

Light AR, Casale EJ, Menétrey DM (1986) The effects of focal stimulation in nucleus raphe magnus and periaqueductal gray on intracellularly recorded neurons in spinal laminae I and II. J Neurophysiol 56:555-571. CrossRef Medline

Lorenz J, Cross DJ, Minoshima S, Morrow TJ, Paulson PE, Casey KL (2002) A unique representation of heat allodynia in the human brain. Neuron 35:383-393. CrossRef Medline

Mayer EA, Berman S, Suyenobu B, Labus J, Mandelkern MA, Naliboff BD, Chang L (2005) Differences in brain responses to visceral pain between patients with irritable bowel syndrome and ulcerative colitis. Pain 115: 398-409. CrossRef Medline

McGarry LM, Carter AG (2016) Inhibitory gating of basolateral amygdala inputs to the prefrontal cortex. J Neurosci 36:9391-9406. CrossRef Medline

Metz AE, Yau HJ, Centeno MV, Apkarian AV, Martina M (2009) Morphological and functional reorganization of rat medial prefrontal cortex in neuropathic pain. Proc Natl Acad Sci U S A 106:2423-2428. CrossRef Medline

Millan MJ (2002) Descending control of pain. Prog Neurobiol 66:355-474. CrossRef Medline

Millecamps M, Centeno MV, Berra HH, Rudick CN, Lavarello S, Tkatch T, Apkarian AV (2007) D-cycloserine reduces neuropathic pain behavior through limbic NMDA-mediated circuitry. Pain 132:108-123. CrossRef Medline

Morgan MM, Gold MS, Liebeskind JC, Stein C (1991) Periaqueductal gray stimulation produces a spinally mediated, opioid antinociception for the inflamed hindpaw of the rat. Brain Res 545:17-23. CrossRef Medline

Morgan MM, Heinricher MM, Fields HL (1992) Circuitry linking opioidsensitive nociceptive modulatory systems in periaqueductal gray and spinal cord with rostral ventromedial medulla. Neuroscience 47:863-871. CrossRef Medline

Naka A, Adesnik H (2016) Inhibitory circuits in cortical layer 5. Front Neural Circuits 10:35. CrossRef Medline

Ossipov MH, Dussor GO, Porreca F (2010) Central modulation of pain. The Journal of clinical investigation 120:3779-3787. CrossRef Medline

Otsuka T, Kawaguchi Y (2009) Cortical inhibitory cell types differentially form intralaminar and interlaminar subnetworks with excitatory neurons. J Neurosci 29:10533-10540. CrossRef Medline

Porreca F, Ossipov MH, Gebhart GF (2002) Chronic pain and medullary descending facilitation. Trends Neurosci 25:319-325. CrossRef Medline

Porro CA, Baraldi P, Pagnoni G, Serafini M, Facchin P, Maieron M, Nichelli 
P (2002) Does anticipation of pain affect cortical nociceptive systems? J Neurosci 22:3206-3214. CrossRef Medline

Qu C, King T, Okun A, Lai J, Fields HL, Porreca F (2011) Lesion of the rostral anterior cingulate cortex eliminates the aversiveness of spontaneous neuropathic pain following partial or complete axotomy. Pain 152: 1641-1648. CrossRef Medline

Rainville P, Duncan GH, Price DD, Carrier B, Bushnell MC (1997) Pain affect encoded in human anterior cingulate but not somatosensory cortex. Science 277:968-971. CrossRef Medline

Rock C, Apicella AJ (2015) Callosal projections drive neuronal-specific responses in the mouse auditory cortex. J Neurosci 35:6703-6713. CrossRef Medline

Schubert D, Staiger JF, Cho N, Kotter R, Zilles K, Luhmann HJ (2001) Layerspecific intracolumnar and transcolumnar functional connectivity of layer V pyramidal cells in rat barrel cortex. J Neurosci 21:3580-3592. Medline

Seltzer Z, Dubner R, Shir Y (1990) A novel behavioral model of neuropathic pain disorders produced in rats by partial sciatic nerve injury. Pain 43: 205-218. CrossRef Medline

Shipley MT, Ennis MT, Rizvi TA, Behbehani MM (1991) Topographical specificity of forebrain inputs to the midbrain periaqueductal gray: Evidence for discrete longitudinally organised input columns. In: The midbrain periaqueductal grey matter: functional, anatomical and neurochemical organization (Depaulis A, Bandler R, eds), pp 417-448. New York, NY: Plenum.

Sierra-Mercado D, Padilla-Coreano N, Quirk GJ (2011) Dissociable roles of prelimbic and infralimbic cortices, ventral hippocampus, and basolateral amygdala in the expression and extinction of conditioned fear. Neuropsychopharmacology 36:529-538. CrossRef Medline

Sinnott CJ, Garfield JM, Strichartz GR (1999) Differential efficacy of intravenous lidocaine in alleviating ipsilateral versus contralateral neuropathic pain in the rat. Pain 80:521-531. CrossRef Medline

Stamford JA (1995) Descending control of pain. Br J Anaesth 75:217-227. CrossRef Medline

Suter BA, O'Connor T, Iyer V, Petreanu LT, Hooks BM, Kiritani T, Svoboda K, Shepherd GM (2010) Ephus: multipurpose data acquisition software for neuroscience experiments. Front Neural Circuits 4:100. CrossRef Medline

Suter BA, Migliore M, Shepherd GM (2013) Intrinsic electrophysiology of mouse corticospinal neurons: a class-specific triad of spike-related properties. Cereb Cortex 23:1965-1977. CrossRef Medline
Tracey I, Mantyh PW (2007) The cerebral signature for pain perception and its modulation. Neuron 55:377-391. CrossRef Medline

Urban MO, Gebhart GF (1999) Supraspinal contributions to hyperalgesia. Proc Natl Acad Sci U S A 96:7687-7692. CrossRef Medline

Valet M, Sprenger T, Boecker H, Willoch F, Rummeny E, Conrad B, Erhard P, Tolle TR (2004) Distraction modulates connectivity of the cingulofrontal cortex and the midbrain during pain: an fMRI analysis. Pain 109: 399-408. CrossRef Medline

van Wijk G, Veldhuijzen DS (2010) Perspective on diffuse noxious inhibitory controls as a model of endogenous pain modulation in clinical pain syndromes. J Pain 11:408-419. CrossRef Medline

Vanegas H, Barbaro NM, Fields HL (1984) Midbrain stimulation inhibits tail-flick only at currents sufficient to excite rostral medullary neurons. Brain Res 321:127-133. CrossRef Medline

Vidal-Gonzalez I, Vidal-Gonzalez B, Rauch SL, Quirk GJ (2006) Microstimulation reveals opposing influences of prelimbic and infralimbic cortex on the expression of conditioned fear. Learn Mem 13:728-733. CrossRef Medline

Villemure C, Schweinhardt P (2010) Supraspinal pain processing: distinct roles of emotion and attention. Neuroscientist 16:276-284. CrossRef Medline

Vos BP, Strassman AM, Maciewicz RJ (1994) Behavioral evidence of trigeminal neuropathic pain following chronic constriction injury to the rat's infraorbital nerve. J Neurosci 14:2708-2723. CrossRef Medline

Wager TD, Rilling JK, Smith EE, Sokolik A, Casey KL, Davidson RJ, Kosslyn SM, Rose RM, Cohen JD (2004) Placebo-induced changes in FMRI in the anticipation and experience of pain. Science 303:1162-1167. CrossRef Medline

Wang GQ, Cen C, Li C, Cao S, Wang N, Zhou Z, Liu XM, Xu Y, Tian NX, Zhang Y, Wang J, Wang LP, Wang Y (2015) Deactivation of excitatory neurons in the prelimbic cortex via Cdk5 promotes pain sensation and anxiety. Nat Commun 6:7660. CrossRef Medline

Wood L, Shepherd GM (2010) Synaptic circuit abnormalities of motorfrontal layer 2/3 pyramidal neurons in a mutant mouse model of Rett syndrome. Neurobiol Dis 38:281-287. CrossRef Medline

Yalcin I, Megat S, Barthas F, Waltisperger E, Kremer M, Salvat E, Barrot M (2014) The sciatic nerve cuffing model of neuropathic pain in mice. J Vis Exp 89. CrossRef Medline

Zhang Z, Gadotti VM, Chen L, Souza IA, Stemkowski PL, Zamponi GW (2015) Role of prelimbic GABAergic circuits in sensory and emotional aspects of neuropathic pain. Cell Rep 12:752-759. CrossRef Medline 